\title{
CORRECTIONS
}

\section{Is Spanish public health sinking?}

Two errors crept into this feature by Aser García Rada (BMJ 2011;343:d7445, doi:10.1136/bmj.d7445). Four regions not three account for $60 \%$ of the health debt (Madrid, Castilla y León, Valencia, and Andalusia), and the final quote in the article should have been more fully attributed to Julio Mayol, a surgeon and innovation director of the Clínico San Carlos Hospital, Madrid.

Cite this as: BMJ 2011;343:d7805

๑ BMJ Publishing Group Ltd 2011 